\title{
Natriuretic peptide tests in suspected acute heart failure
}

\author{
A reliable tool for assessing acutely breathless patients
}

\author{
Frans H Rutten associate professor of general practice, Arno W Hoes professor of clinical \\ epidemiology and general practice
}

Julius Center for Health Sciences and Primary Care, University Medical Center Utrecht, Utrecht, Netherlands

Heart failure should always be considered in patients with shortness of breath and reduced exercise tolerance, especially older people, and irrespective of comorbidities such as chronic obstructive pulmonary disease. ${ }^{1}$ Symptoms and signs are rarely enough for diagnosis, and additional investigations usually follow. ${ }^{2}$ Measuring the serum concentration of natriuretic peptides improves diagnostic accuracy in patients with suspected heart failure in the non-acute setting, ${ }^{3-5}$ and evidence for these tests also being helpful in patients with suspected acute heart failure is growing.

International guidelines now recommend measuring natriuretic peptide concentrations, and set age independent but different exclusionary thresholds for the acute and non-acute setting. ${ }^{2}$ Although age independent thresholds are an attractive option in daily practice, their diagnostic accuracy has not yet been established. In a linked diagnostic meta-analysis (doi:10.1136/ bmj.h910), Roberts and colleagues evaluated thresholds for plasma B type natriuretic peptide (BNP, $\leq 100 \mathrm{ng} / \mathrm{L}$ ), N terminal probrain natriuretic peptide (NTproBNP, $\leq 300 \mathrm{ng} / \mathrm{L}$ ), and mid-regional proatrial natriuretic peptide (MRproANP, $\leq 120$ $\mathrm{pmol} / \mathrm{L}$ ) recommended for excluding heart failure in acute care settings such as emergency departments. ${ }^{6}$ Their conclusion that natriuretic peptide concentrations below these thresholds rule out heart failure, with and without reduced ejection fraction, is a major step towards routine use of these tests in emergency departments and the safe but rapid assessment of patients presenting with subacute or acute breathlessness.

Natriuretic peptides are a family of vasoactive hormones produced by myocytes in response to stretch or increased wall tension primarily caused by the pressure or volume overload present in decompensated heart failure. ${ }^{7}$ In line with Laplace's law (wall tension=pressure $\times$ radius/wall thickness), the production of natriuretic peptides will in general be higher in heart failure with reduced ejection fraction (loss of myocytes followed by left ventricular dilation and wall thinning) than in heart failure with preserved ejection fraction (myocardial dysfunction followed by interstitial fibrosis and left ventricular wall thickening). ${ }^{8}$
These peptides are clearly a good candidate for a diagnostic test for heart failure in acute hospital settings; but are the firm conclusions drawn by Roberts and colleagues justified? After a systematic search, the authors selected 37 unique study cohorts for review and extracted data on the number of true positives and negatives and false positives and negatives. Their reference standard was clinical diagnosis based on suggestive symptoms and signs, plus abnormality of cardiac structure or function assessed by echocardiography, and related to a reduced ejection fraction or to diastolic dysfunction with preserved ejection fraction. ${ }^{2}$ They assessed the quality of each individual study using the QUADAS-II checklist. ${ }^{9}$ Weaknesses in some of the studies included poor masking of test results when determining the reference standard diagnosis, inappropriate sequencing of tests, and failure to deal with missing values or explain withdrawals. ${ }^{6}$ But these limitations are unlikely to have biased the findings.

The meta-analysis included only studies that evaluated the diagnostic performance of natriuretic peptides in isolation, unlike clinical practice where a diagnosis is virtually never based on one diagnostic test. Diagnosis typically emerges from history, examination, imaging, and tests in a natural hierarchy-for example, signs and symptoms of heart failure followed by electrocardiography, measurement of natriuretic peptides, and chest radiography. ${ }^{1}$ The authors had no information on the diagnostic accuracy of individual signs, symptoms, or other diagnostic tests, and individual studies in their review did not evaluate the performance of a diagnostic pathway. So the true added value of natriuretic peptides remains to be quantified.

Although a single cut-off value to rule out heart failure is preferable for ease of use, doctors considering using these tests will also need reassurance that the threshold is valid in subgroups such as older patients and those with specific comorbidities. Although the study level data reported by Roberts and colleagues does not allow for important subgroup analyses, individual patient data (IPD) meta-analysis, where the individual data of all participants in all studies are combined would be a valuable next step. IPD meta-analysis would help identify 
subgroups in whom the recommended rule-out thresholds were more or less accurate. ${ }^{10}$ IPD meta-analysis could also be used to quantify the value of natriuretic peptides in addition to symptoms and signs. ${ }^{311}$

Despite the lack of subgroup analyses or evidence of added value in their systematic review, Roberts and colleagues' conclusions that natriuretic peptide concentrations below recommended thresholds can safely and reliably rule out heart failure in the acute setting is justified; the negative predictive values are high. ${ }^{2}$

What about the role of natriuretic peptides in the non-acute setting? Adults with slow onset heart failure typically present to primary care, and studies suggest that measuring natriuretic peptide concentrations can also be useful in this setting; using lower thresholds than those used in acute settings ( $35 \mathrm{ng} / \mathrm{L}$ for BNP and $125 \mathrm{ng} / \mathrm{L}$ for NTproBNP). ${ }^{2-13}$ Supporting evidence is incomplete however, and recommended thresholds for excluding heart failure have not yet been fully evaluated. ${ }^{11}{ }^{14}$

Routine use of tests for natriuretic peptides will improve the management of patients with acute breathlessness. These tests help doctors rule out heart failure quickly and identify those who would benefit from additional confirmatory tests, typically echocardiography. A meta-analysis of studies done in ambulatory settings is now needed, preferably using IPD, to strengthen the evidence underpinning rule-out thresholds recommended for patients presenting less acutely.

Competing interests: We have read and understood the BMJ policy on declaration of interests and declare the following: none.

Provenance and peer review: Commissioned; not externally peer reviewed.
1 Rutten FH, Moons KG, Cramer MJ, Grobbee DE, Zuithoff NP, Lammers JW, et al. Recognising heart failure in elderly patients with stable chronic obstructive pulmonary disease in primary care: cross-sectional diagnostic study. BMJ 2005;331:1379.

2 McMurray JJV, Adamopoulos S, Anker SD, Auricchio A, Bohm M, Dickstein K, et al. ESC guidelines for the diagnosis and treatment of acute and chronic heart failure 2012. Eur $J$ Heart Fail 2012;14:803-69.

3 Zaphiriou A, Robb S, Murray-Thomas T, Mendez G, Fox K, McDonagh T, et al. The diagnostic accuracy of plasma BNP and NTproBNP in patients referred for primary care with suspected heart failure: results of the UK natriuretic peptide study. Eur J Heart Fail 2005;7:537-41.

4 Fuat A, Murphy JJ, Hungin AP, Curry J, Mehrzad AA, Hetherington A, et al. The diagnostic accuracy and utility of a B-type natriuretic peptide test in a community population of patients with suspected heart failure. Br J Gen Pract 2006;56:327-33.

5 Cowie MR, Struthers AD, Wood DA, Coats AJ, Thompson SG, Poole-Wilson PA, et al. Value of natriuretic peptides in assessment of patients with possible new heart failure in primary care. Lancet 1997;350:1349-53.

6 Roberts E, Ludman AJ, Dworzynski K, Al-Mohammad A, Cowie MR, McMurray JJV, et al. The diagnostic accuracy of the natriuretic peptides in heart failure: systematic review and diagnostic meta-analysis in the acute setting. BMJ 2015;350;h910.

7 Levin ER, Garner DG, Samson WK Natriuretic peptides. N Engl J Med 1998;339;321-8.

8 Paulus WJ, Tschoepe C. A novel paradigm for heart failure with preserved ejection fraction: Paulus WJ, Tschoepe $\mathrm{C}$. A novel paradigm for heart failure with preserved ejection fraction:
comorbidities drive myocyte dysfunction and remodeling through coronary microvascular endothelial inflammation. J Am Coll Cardiol 2013;62:263-71.

9 Whiting PF, Rutjes AW, Westwood ME, Mallett S, Deeks JJ, Reitsma JB, et al. Quadas-2: a revised tool for the quality assessment of diagnostic accuracy studies. Ann Intern Med 2011;155;529-36.

10 Geersing GJ, Zuithoff NP, Kearon C, Anderson DR, Ten Cate-Hoek AJ, Elf JL, et al. Exclusion of deep vein thrombosis using the Wells rule in clinically important subgroups: Individual patient meta-analysis. BMJ 2014;348:g1340.

11 Mant J, Doust J, Roalfe A, Barton P, Cowie MR, Glasziou P, et al. Systematic review and individual patient data meta-analysis of diagnosis of heart failure, with modelling of implications of different diagnostic strategies in primary care. Health Technol Assess 2009;13:1-207.

12 Kelder JC, Cramer MJ, Verweij WM, Grobbee DE, Hoes AW. Clinical utility of three B-type natriuretic assays for the initial diagnostic assessment of new slow-onset heart failure. $J$ Card Fail 2011;17:729-34.

13 Gustafsson F, Steensgaard-Hansen F, Badskjaer J, Poulsen AH, Corell P, Hildebrandt $\mathrm{P}$. Diagnostic and prognostic performance of $\mathrm{N}$-terminal proBNP in primary care patients with suspected heart failure. J Card Fail 2005;11:S15-20.

14 Kelder JC, Cowie MR, McDonagh TA, Hardman SM, Grobbee DE, Cost B, et al. Quantifying the added value of BNP in suspected heart failure in general practice: an individual patients data meta-analysis. Heart 2011;97:959-63.

Cite this as: BMJ 2015;350:h1164

๑ $\odot$ BMJ Publishing Group Ltd 2015 